\title{
Dampak Ekonomi dan Strategi Pengembangan Wisata Danau Sentani di Kabupaten Jayapura
}

\author{
Economic Impacts and Development Strategies for Lake Sentani Tourism \\ in Jayapura Regency
}

\author{
Ditha Mangiri $^{1^{*}}$, Hermanto Siregar ${ }^{2} \&$ Ernan Rustiadi $^{3}$ \\ ${ }^{1}$ Program Studi Ilmu Perencanaan Pembangunan Wilayah dan Perdesaan, Institut Pertanian Bogor, Jalan \\ Kamper, Kampus IPB Dramaga, Bogor 16680, Indonesia; ${ }^{2}$ Departemen Ilmu Ekonomi, Fakultas Ekonomi \\ dan Manajemen, Institut Pertanian Bogor, Jalan Kamper, Kampus IPB Dramaga, Bogor 16680, Indonesia; \\ ${ }^{3}$ Departemen Ilmu Tanah dan Sumberdaya Lahan, Fakultas Pertanian, Institut Pertanian Bogor, Jalan \\ Meranti, Kampus IPB Dramaga, Bogor 16680, Indonesia; \\ *Penulis korespondensi. e-mail: dithamangiri25@gmail.com \\ (Diterima: 25 September 2019; Disetujui: 24 Desember 2019)
}

\begin{abstract}
Lake Sentani tourism is a type of natural tourism. Management of the natural tourism is in the form of collaboration between the local government and local communities by relying on the beauty and panorama of the nature. Aims of this study are (1) to estimate the economic value of Lake Sentani tourism which is expected to have an impact to the local economy and benefit the surrounding communities, and (2) to formulate effective strategies for managing the natural tourism. Data collection was conducted through field survey and interview. Data used were on tourist expenditure, labor, business income, number of tourists, and perceptions and preferences of stakeholders towards the development of Lake Sentani tourism. The sampling method used was the purposive sampling technique with a total sample of 133 persons. The method of analysis used were Individual Travel Cost Method (ITCM), multiplier effect, and Analytic Hierarchy Process (AHP). Analysis results show that Lake Sentani tourism had a low economic impact on the local economy development and communities around the area with a value of Keynesian income multiplier of 0.93. In order to develop Lake Sentani tourism, the proposed strategy is ecologically based, supported by the role of local government stakeholder as regulator who are responsible for advancing the welfare of business people involved in all activities related to Lake Sentani tourism.
\end{abstract}

Keywords: development strategy, economic impact, Lake Sentani tourism, multiplier effect

\section{ABSTRAK}

Wisata Danau Sentani merupakan jenis wisata alam. Pengelolaan wisata alam tersebut berbentuk kolaborasi antara Pemerintah Daerah dan masyarakat lokal dengan mengandalkan keindahan dan panorama alam. Tujuan penelitian ini adalah (1) mengestimasi nilai ekonomi wisata Danau Sentani yang diperkirakan memberikan dampak ekonomi lokal dan manfaat terhadap masyarakat sekitar kawasan, serta (2) merumuskan arahan strategi yang efektif dalam pengelolaan wisata alam tersebut. Metode pengambilan data dilakukan melalui survei dan wawancara. Data yang digunakan adalah data pengeluaran wisatawan, tenaga kerja, pendapatan usaha, data jumlah wisatawan, dan data persepsi dan preferensi stakeholder terhadap pengembangan wisata Danau Sentani. Metode pengambilan sampel menggunakan teknik purposive sampling dengan jumlah sampel sebanyak 133 orang. Metode analisis menggunakan Individual Travel Cost Method 
(ITCM), multiplier effect (efek pengganda), dan Analytic Hierarchy Process (AHP). Hasil analisis menunjukkan wisata Danau Sentani menghasilkan dampak ekonomi yang masih rendah terhadap pengembangan ekonomi lokal dan masyarakat sekitar kawasan dengan nilai keynesian income multiplier 0.93. Untuk mengembangkan wisata Danau Sentani strategi, diusulkan berbasis ekologi, didukung peran stakeholder Pemerintah Daerah sebagai pembuat regulasi dan pihak yang bertanggung jawab untuk memajukan kesejahteraan para pelaku usaha yang terlibat di dalam seluruh aktivitas terkait wisata Danau Sentani.

Kata kunci: dampak ekonomi, multiplier effect, strategi pengembangan, wisata Danau Sentani

\section{PENDAHULUAN}

Pembangunan wilayah adalah upaya pemerintah dalam mewujudkan keadilan dan pembangunan nasional bagi seluruh wilayah nusantara. Salah satu sektor pengembangan wilayah yang memiliki kontribusi penting adalah sektor pariwisata. Pariwisata merupakan salah satu sektor ekonomi penting dalam pembangunan nasional karena dapat meningkatkan kesejahteraan masyarakat, membuka lapangan pekerjaan, serta merangsang pertumbuhan ekonomi regional (Yakup, 2019). Pertumbuhan ekonomi diartikan sebagai pertambahan pendapatan masyarakat secara keseluruhan yang terjadi di suatu wilayah (Tarigan, 2007). Pertumbuhan ekonomi merupakan suatu keharusan untuk mengurangi kemiskinan (Siregar \& Dwi, 2008).

Strategi pembangunan daerah merupakan gabungan pendekatan sektoral dan pendekatan spasial dalam rangka terwujudnya keberimbangan pembangunan wilayah (Rustiadi et al., 2011) yang artinya pengembangan pariwisata harus didasarkan pada aspek tata ruang wilayah. Salah satu bentuk wilayah yang memiliki potensi wisata adalah wilayah Kabupaten. Kabupaten Jayapura merupakan bentuk wilayah yang memiliki potensi wisata yang sangat beragam dan memiliki prospek yang sangat besar untuk dikembangkan sebagai sektor unggulan dalam pengembangan ekonomi wilayahnya. Potensi lokal adalah segala kekuatan dan kemampuan yang dimiliki oleh suatu daerah dari berbagai aspek yang memungkinkan untuk dikembangkan dalam mencapai tujuan pembangunan (Soleh, 2017).

Jenis wisata yang terdapat di Kabupaten Jayapura yaitu meliputi wisata alam, wisata budaya, religi, sejarah, dan berbagai bentuk lainnya. Salah satu jenis wisata alam yang terdapat di Kabupaten Jayapura yaitu berupa wisata Danau Sentani. Danau Sentani yang terletak di Kabupaten Jayapura yang merupakan danau terbesar di Provinsi Papua dengan luas sekitar 9,360 hektar dengan kedalaman rata-rata 52 m dan terletak pada ketinggian 75 m diatas permukaan laut serta berada dibawah lereng Pegunungan Cagar Alam Cyclops yang memiliki luas sekitar 245,000 hektar (Walukow et al., 2008).

Bentuk keanekaragaman hayati yang terdapat di Danau Sentani terdiri dari 21 buah pulau kecil yang mengelilingi danau tersebut, sumberdaya ikan danau yang sangat besar, kualitas air yang sangat jernih dan bersih sehingga dapat dimanfaatkan oleh masyarakat lokal sebagai air minum. Potensi lain yang mendukung wisata Danau Sentani sebagai wisata yang sangat terkenal di Kabupaten Jayapura, Kota Jayapura, dan berbagai wilayah lainnya di Provinsi Papua adalah ketersediaan sarana dan prasarana transportasi umum yang sangat memadai, angkutan sungai antar kampung, keramahan masyarakat, ketersediaan infrastruktur utama dan pendukung wisata sudah semakin baik, dan pelaksanaan Festival Danau Sentani (FDS).

Data jumlah wisatawan yang berkunjung ke Danau Sentani pada tahun 2017 mencapai 59,226 orang meningkat sebanyak 3,130 orang pada tahun 2018 sehingga jumlahnya mencapai 
62,356 orang (Dinas Pariwisata dan Kebudayaan Kabupaten Jayapura, 2019). Tingginya potensi objek wisata dan daya tarik alam dalam kawasan Danau sentani memberikan dampak terhadap tingginya jumlah wisatawan baik wisatawan nusantara maupun wisatawan asing yang datang berkunjung ke lokasi wisata alam ini. Dengan keunikan bentangan alam dan budaya banyak mengundang wisatawan untuk datang menikmati wisata alam tersebut dengan sendirinya akan memberikan dampak kepada masyarakat di sekitarnya selanjutnya dengan sendirinya hal ini akan memberikan pengaruh terhadap perekonomian wilayah melalui aktivitas belanja yang dilakukan oleh wisatawan. Pengaruh ekonomi wisata alam terhadap wilayah diketahui dengan mengikuti aliran pola pembelanjaan pengunjung, kontribusinya terhadap jumlah penjualan, pendapatan, pekerjaan, dan penerimaan dalam ekonomi wilayah amatan.

Pola pembelanjaan pengunjung pada umumnya menunjukkan pembelian barang dan layanan, baik dari ekonomi lokal maupun luar wilayah. Pola pembelanjaan pengunjung tersebut mengindikasikan pengaruh langsung terhadap sektor pariwisata. Keberadaan wisata tersebut di wilayah Danau Sentani dapat menghasilkan dampak ekonomi wilayah, mengerakkan sektor-sektor ekonomi lainnya, dan peningkatan kesejahteraan masyarakat. Dampak ekonomi dari wisata tersebut akan terus mengalami peningkatan apabila didukung dengan keterlibatan seluruh stakeholder terkait dalam rangka mengembangkan wisata Danau Sentani menjadi lebih terkenal di wilayah Papua hingga mancanegara tetapi diperlukan juga alternatif pengelolaan Danau sehingga pemanfaatan Danau Sentani dapat terkendali.

Wisata Danau Sentani selama ini belum diketahui apakah memberikan nilai dan dampak ekonomi yang efektif untuk meningkatkan perekonomian masyarakat, juga perlu diketahui secara lebih rinci aktivitas apa yang berdampak paling tinggi dan berpengaruh langsung, dampak terhadap penerimaan masyarakat, dan seberapa banyak kebocoran ekonomi yang dihasilkan. Oleh karena itu dibutuhkan suatu analisis yang mendalam untuk mengukur nilai ekonomi wisata dan dampaknya serta alternatif kebijakan dalam pengembangan wisata Danau Sentani kedepan.

\section{METODE PENELITIAN.}

Penelitian dilakukan di Kawasan Wisata Danau Sentani yang terletak di Kabupaten Jayapura pada bulan Februari hingga April 2019.
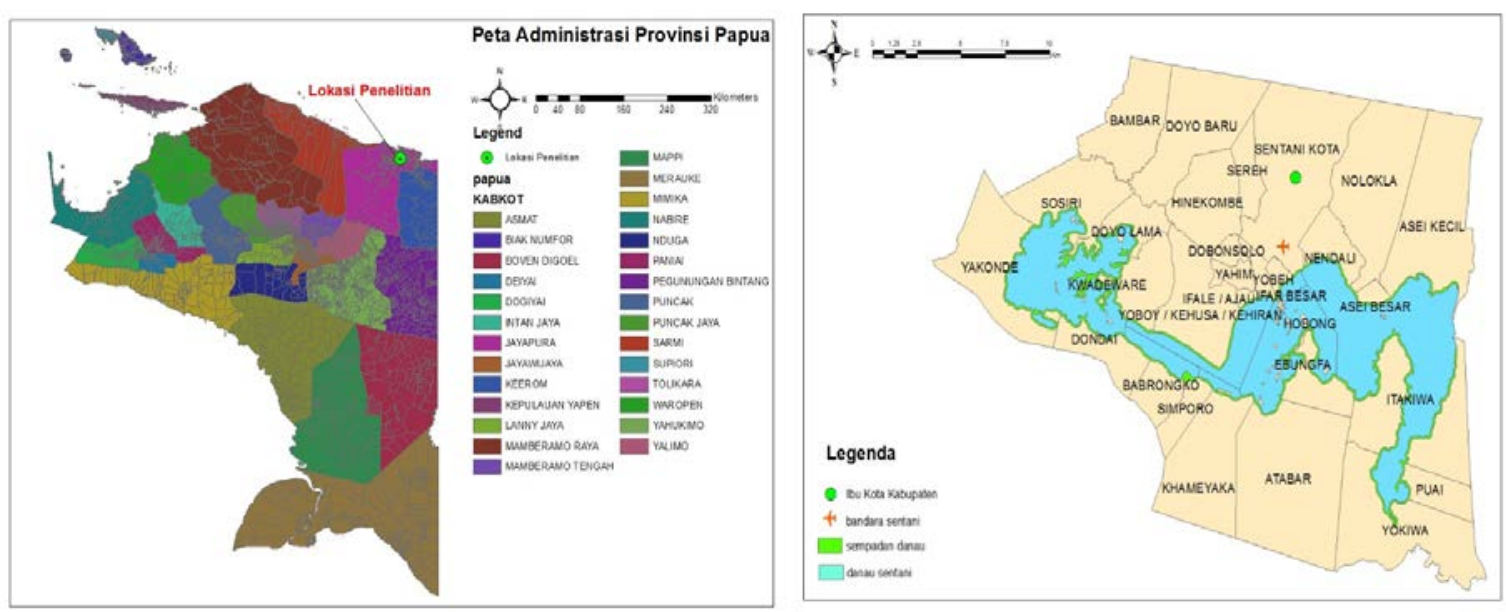

Gambar 1. Peta lokasi penelitian Sumber: Bappeda Kabupaten Jayapura 
Jenis data yang digunakan dalam penelitian ini adalah data primer yang diperoleh dengan melakukan survei dan wawancara yang dilakukan oleh peneliti pada wisatawan, tenaga kerja, unit usaha sekitar kawasan wisata Danau Sentani dan beberapa stakeholder terkait pengembangan Danau Sentani. Data sekunder diperoleh dari pihakpihak instansi terkait objek penelitian seperti Dinas Kebudayaan dan Pariwisata Provinsi Papua, Dinas Kebudayaan dan Pariwisata Kabupaten Jayapura, Badan Perencanaan dan Pembangunan Daerah Kabupaten Jayapura, serta laporan studi penelitian dan publikasi ilmiah.

Metode penarikan sampel dengan menggunakan metode purposive sampling. Sampel penelitian yakni 100 orang wisatawan, 17 orang pelaku usaha, 10 orang tenaga kerja, dan 6 orang stakeholder. Metode analisis yang digunakan untuk menganalisis nilai ekonomi wisata Danau Sentani yakni dengan menggunakan metode Individual Travel Cost Method (ITCM). Metode ITCM yang digunakan adalah dengan menghitung surplus konsumen wisatawan (Clawson \& Knetsch, 1966 dalam Fauzi, 2014). Surplus konsumen diperoleh dengan mengetahui koefisien $\beta_{0}$ dan $\beta_{1}$ serta choke price (Fauzi, 2014) dengan fungsi rumus di bawah ini:

$$
\mathrm{CS}=(\beta 0-\beta 1 \mathrm{TC}) / 2 \beta_{1}
$$

Koefisien-koefisien tersebut diperoleh dari hasil regresi linier berganda dengan enam variabel bebas yaitu biaya perjalanan, pendapatan wisatawan, jarak tempuh wisatawan dari rumah menuju lokasi wisata, kebersihan lingkungan di lokasi wisata, usia, dan pendidikan terhadap variabel terikat yaitu jumlah kunjungan dalam satu tahun terakhir. Dengan menggunakan Software SPSS Versi 23 fungsi permintaan atau jumlah kunjungan sebagai berikut diestimasi dengan metode Ordinary Least Square (OLS). $\beta_{0}$ dan $\beta_{1}$ pada persamaan CS diperoleh masing-masing dari intersep dan koefisien regresi BP pada fungsi permintaan tersebut.

$$
\mathrm{Y}=\mathrm{f}(\mathrm{BP}, \mathrm{JR}, \mathrm{PD}, \mathrm{KL}, \mathrm{US}, \mathrm{PN})
$$

Nilai ekonomi diestimasi dengan mengalikan nilai surplus konsumen rata-rata individu dengan total kunjungan pada tahun 2018 dengan fungsi rumus:

$$
\mathrm{NE}=\mathrm{CSi} \mathrm{x} \mathrm{Vt}
$$

Analisis dampak ekonomi wisata Danau Sentani yakni dengan menggunakan metode multiplier effect oleh META (2001). Metode yang digunakan menghitung dampak langsung yakni pengeluaran wisatawan langsung masuk ke usaha masyarakat lokal, selanjutnya dampak tidak langsung yakni menghitung pengeluaran pihak pengelola untuk membayar upah tenaga kerja, dan̄ dampak lanjutan yakni menghitung perubahan aktivitas ekonomi di lokasi wisata dari pembelanjaan tenaga kerja tersebut untuk memenuhi kebutuhannya dengan menggunakan Sofware Excel 2013 dengan fungsi rumus:

Keynesian Income Multiplier $=(D+N+U) / \mathrm{E}$

Ratio Income Multiplier Tipe $\mathrm{I}=(D+N) / \mathrm{D}$

Ratio Income Multiplier Tipe II $=(D+N+U) / \mathrm{D}$

Keterangan:

$\mathrm{E}=$ tambahan pengeluaran pengunjung (Rp)

$\mathrm{D}=$ pendapatan lokal yang diperoleh secara langsung dari E (Rp)

$\mathrm{N}$ = pendapatan lokal yang diperoleh secara tidak langsung dari E (Rp)

$\mathrm{U}=$ pendapatan lokal yang diperoleh secara induced dari $\mathrm{E}(\mathrm{Rp})$.

Analisis strategi pengelolaan Danau Sentani yakni menggunakan metode AHP oleh (Saaty, 1994). Metode yang digunakan yakni menilai persepsi dan preferensi dari stakeholder dengan menggunakan Sofware Expert Choice 11 .

\section{HASIL DAN PEMBAHASAN}

\section{Nilai Ekonomi Danau Sentani}

Nilai ekonomi adalah hal yang penting untuk diketahui dari adanya objek wisata Danau Sentani, nilai ekonomi yang diperoleh dapat 
menunjukkan besarnya manfaat dari objek wisata tersebut. Nilai ekonomi wisata Danau Sentani diestimasi menggunakan Individual Travel Cost Method (ITCM) dengan menghitung surplus konsumen wisatawan. Hasil regresi fungsi permintaan terdapat pada Tabel 1.

Tabel 1. Hasil pendapatan fungsi permintaan kunjungan wisata Danau Sentani

\begin{tabular}{llll}
\hline Variabel & Koefisien & Sig & VIF \\
\hline Constant & .297 & .746 & \\
Biaya Perjalanan (BP) & -.399 & $.000^{* * *}$ & 1.670 \\
Jarak (JR) & -.185 & $.017^{* *}$ & 2.223 \\
Pendapatan wisatawan (PD) & .231 & $.018^{* *}$ & 1.434 \\
Kebersihan (KL) & .288 & $.000^{* * *}$ & 1.413 \\
Usia (US) & -.039 & .677 & 2.147 \\
Pendidikan (PN) & .141 & $.061^{*}$ & 1.350 \\
$R$ Square (R $\left.\mathrm{R}^{2}\right)$ & $61.9 \%$ & & \\
Adjusted R Square $\left(\mathrm{R}^{2}\right.$ adj) & $59.5 \%$ & & \\
\hline
\end{tabular}

Besarnya nilai ekonomi wisatawan kunjungan adalah sebesar Rp14,035. Informasi terhadap wisata Danau Sentani ditunjukkan lebih lanjut terdapat pada Tabel 2. dengan nilai surplus konsumen wisatawan per

Tabel 2. Perhitungan nilai ekonomi wisata Danau Sentani

\begin{tabular}{lll}
\hline Keterangan & Satuan & Nilai \\
\hline Jumlah kunjungan responden & kali/tahun & 250 \\
Total kunjungan tahun 2018 & kali/tahun & 62,356 \\
$B_{0}$ & - & .297 \\
$\beta_{1}$ & - & -.399 \\
Choke Price & $\mathrm{Rp}$ & $3,500,000$ \\
$R^{2}$ & persen & $61.9 \%$ \\
$R^{2}$-adj & persen & $59.5 \%$ \\
CS (Surplus Konsumen) & $\mathrm{Rp}$ & $3,508,771$ \\
Rataan CS perindividu & $\mathrm{Rp}$ & 14,035 \\
\hline Nilai Ekonomi Danau Sentani & $\mathrm{Rp}$ & $875,166,460$ \\
\hline
\end{tabular}

Nilai ekonomi wisata yang diperoleh berdasarkan surplus konsumen wisatawan yaitu sebesar Rp875,166,460. Hasil penelitian Ritonga et al., (2018) menunjukkan nilai ekonomi wisata Danau Naga di kabupaten Siak Provinsi Riau sebesar Rp107,955,325/tahun. Hal tersebut menunjukkan bahwa nilai pengeluaran wisatawan di Danau Sentani Kabupaten Jayapura lebih tinggi dibandingkan di daerah Kabupaten Siak. Tingginya pengeluaran di daerah Sentani disebabkan oleh tingkat kemahalan harga bahan baku, biaya transportasi, penginapan, konsumsi, souvenir, sewa speedboat, biaya parkir, dan lain sebagainya, yang mencapai $200 \%$.

\section{Dampak Ekonomi Wisata Danau Sentani}

Dampak ekonomi wisata Danau Sentani ditinjau dari tiga aspek yaitu: 1) dampak ekonomi langsung, 2) dampak ekonomi tidak langsung, dan 3) dampak ekonomi lanjutan. Dampak ekonomi wisata diukur melalui jumlah pengeluaran wisatawan yang terdapat selama wisatawan berada di dalam kawasan wisata tersebut. Informasi lebih lanjut tentang pengeluaran wisatawan terdapat dalam Tabel 3. Jumlah pengeluaran wisatawan di dalam kawasan sebesar Rp140,305 yang terdiri dari pengeluaran pembelian souvenir, pengeluaran konsumsi, dan pengeluaran sewa speedboat 
Tabel 3. Pengeluaran wisatawan

\begin{tabular}{lll}
\hline Biaya per kunjungan & $\begin{array}{l}\text { Rata-rata Pengeluaran } \\
\text { (i) (Rp) }\end{array}$ & $\begin{array}{c}\text { Proporsi (\%) } \\
\text { (ii=i/c*100) }\end{array}$ \\
\hline $\begin{array}{l}\text { Pengeluaran di luar kawasan } \\
\text { Transportasi }\end{array}$ & 58,410 & 25 \\
Konsumsi di luar kawasan & 26,111 & 11.1 \\
Penginapan & 8,500 & 3.6 \\
\hline Jumlah Kebocoran (a) & \multicolumn{3}{l}{39.8} \\
\hline Pengeluaran di dalam kawasan & 93,021 & 19 \\
\hline Konsumsi di dalam kawasan & 44,500 & 18 \\
Parkir & 4,300 & 35.3 \\
Souvenir & 82,373 & 3.3 \\
Speedboat & 7,900 & 0.5 \\
Lainnya & 1,232 & 83.3 \\
\hline Jumlah pengeluaran di dalam kawasan (b) & 140,305 & 100 \\
\hline Jumlah pengeluaran wisatawan (c) & 233,326 & \\
\hline Jumlah kunjungan tahun 2018 (d) & 62,356 & \\
\hline Total pengeluaran wisatawan per tahun di dalam dan di luar & $14,549,276,056$ \\
kawasan (f) & & \\
\hline Total kebocoran pertahun (g) & $5,790,611,870$ & \\
\hline
\end{tabular}

Jumlah pengeluaran wisatawan lainnya juga terdapat di luar kawasan sebesar Rp93,021. Total pengeluaran wisatawan sebesar Rp233,326, artinya bahwa apabila sektor pariwisata Danau Sentani dikembangkan dengan baik dan dengan menggunakan konsep pengelolaan wisata yang efisien, maka akan dapat meningkatkan pendapatan masyarakat dan penerimaan daerah.

\section{Dampak ekonomi langsung}

Dampak ekonomi langsung wisatawan yaitu terjadinya perputaran uang di dalam kawasan yang dikeluarkan oleh wisatawan untuk dapat menikmati fasilitas, wahana, atraksi, dan berbagai akomodasi yang disediakan oleh masyarakat. Bentuk pengeluaran wisatawan umumnya dilakukan secara kontan (cash) di setiap wahana yang digunakan oleh wisatawan.

Dampak ekonomi langsung dari pengeluaran wisatawan yang terdapat di kawasan Danau Sentani terdiri dari dua bentuk pengeluaran yaitu pada aktivitas reguler dan occasional. Reguler yang berarti pengeluaran yang berlangsung di kawasan wisata pada saat wisatawan berkunjung ke lokasi dan occasional pada saat pelaksanaan Festival Danau Sentani (FDS) yang dilaksanakan oleh pemerintah daerah Kabupaten Jayapura setiap tahunnya. Informasi lebih lanjut terdapat dalam Tabel 4.

Tabel 4. Dampak ekonomi langsung wisata Danau Sentani per tahun

\begin{tabular}{lllc}
\hline Unit Usaha & $\begin{array}{l}\text { Jumlah } \\
\text { Populasi (a) }\end{array}$ & $\begin{array}{l}\text { Rata-rata pendapatan } \\
\text { (Rp/tahun) (b) }\end{array}$ & $\begin{array}{l}\text { Dampak ekonomi } \\
\text { langsung (c=a*b) }\end{array}$ \\
\hline Reguler & & & $918,000,000$ \\
\hline Warung Kelontong & 6 & $153,000,000$ & $1,080,000,000$ \\
Rumah Makan & 5 & $216,000,000$ & $2,160,000,000$ \\
Restoran & 2 & $1,080,000,000$ & $410,000,000$ \\
Souvenir & 10 & $41,000,000$ & $243,000,000$ \\
Speedboat & 5 & $48,600,000$ & $315,000,000$ \\
Pedagang Asongan & 10 & $63,000,000$ & $192,000,000$ \\
Angkutan Roda Dua (Ojek) & 10 & $19,200,000$ & $5,318,000,000$ \\
\hline Total Reguler & & & $125,000,000$ \\
\hline Occasional & & & $520,000,000$ \\
\hline Speedboat & 25 & $5,000,000$ & $645,000,000$ \\
Unit Usaha (Stand) & 100 & $5,200,000$ & $5,963,000,000$ \\
\hline Total Occasional & & & \\
\hline Total Keseluruhan & & &
\end{tabular}


Tujuan dari pelaksanaan FDS adalah sebagai upaya pemerintah daerah Kabupaten Daerah untuk mempromosikan Danau Sentani bagi wisatawan lokal dan mancanegara.

\section{Dampak ekonomi tidak langsung}

Dampak ekonomi tidak langsung terdiri dari pengeluaran dari setiap unit usaha dan pendapatan tenaga kerja lokal. Pengeluaran unit usaha dibagi atas biaya variabel dan biaya tetap. Pengeluaran terbesar pelaku usaha adalah untuk pembelian bahan baku. Informasi tentang dampak ekonomi tidak langsung terdapat pada Tabel 5. Pengeluaran unit usaha terbesar adalah unit usaha restoran dan rumah makan dengan masing-masing pengeluaran sebesar Rp607,200,000 dan Rp206,300,000, sedangkan pengeluaran terendah yaitu unit usaha (stand) sebesar Rp990,000. Unit usaha tersebut juga mempekerjakan karyawan/tenaga kerja yaitu untuk usaha rumah makan dan restoran dengan jumlah pendapatan sebesar Rp24,000,000 dan Rp30,000,000/tahun.

Tabel 5. Dampak ekonomi tidak langsung

\begin{tabular}{|c|c|c|c|c|}
\hline Jenis Usaha & $\begin{array}{l}\text { Populasi } \\
\text { TK } \\
\text { (orang) }\end{array}$ & $\begin{array}{l}\text { Pendapatan TK } \\
\text { (Rp/tahun) }\end{array}$ & $\begin{array}{l}\text { Pengeluaran unit usaha } \\
\text { di kawasan (Rp/tahun) }\end{array}$ & $\begin{array}{l}\text { Dampak } \\
\text { Ekonomi tidak } \\
\text { langsung (Rp) }\end{array}$ \\
\hline \multicolumn{5}{|l|}{ Unit Usaha (Reguler) } \\
\hline Warung Kelontong & 1 & 0 & $105,450,000$ & $105,450,000$ \\
\hline Rumah Makan & 13 & $24,000,000$ & $206,300,000$ & $518,300,000$ \\
\hline Restoran & 15 & $30,000,000$ & $607,200,000$ & $1,057,200,000$ \\
\hline Souvenir & 1 & 0 & $44,750,000$ & $44,750,000$ \\
\hline Speedboat & 1 & 0 & $26,420,000$ & $26,420,000$ \\
\hline Pedagang Asongan & 1 & 0 & $79,100,000$ & $79,100,000$ \\
\hline Angkutan Roda Dua (Ojek) & 1 & 0 & $45,000,000$ & $45,000,000$ \\
\hline \multicolumn{5}{|l|}{ Unit Usaha (Occasional) } \\
\hline Speedboat & 1 & 0 & $1,766,666$ & $1,766,666$ \\
\hline Unit Usaha (Stand) & 1 & 0 & 990,000 & 990,000 \\
\hline Total (A) & & & & $1,878,976,667$ \\
\hline \multicolumn{5}{|l|}{ Tenaga Kerja } \\
\hline Kebersihan & 12 & 800,000 & 0 & $9,600,000$ \\
\hline Karcis FDS & 5 & 500,000 & 0 & $2,500,000$ \\
\hline Keamanan & 10 & $1,500,000$ & 0 & $1,500,000$ \\
\hline Petugas Parkir & 10 & 600,000 & 0 & $6,000,000$ \\
\hline Penjaga Toilet & 8 & 500,000 & 0 & $4,000,000$ \\
\hline Tim Pelaksana & 20 & $1,000,000$ & 0 & $20,000,000$ \\
\hline Total (B) & & & & $57,100,000$ \\
\hline Total Keseluruhan & & & & $1,936,076,667$ \\
\hline
\end{tabular}

\section{Dampak Ekonomi Lanjutan}

Dampak ekonomi lanjutan kawasan wisata Danau Sentani juga menghasilkan dampak lanjutan atau induct impact. Dampak ekonomi lanjutan merupakan pengeluaran tenaga kerja setiap harinya pada waktu jam kerja, yaitu berupa biaya transportasi, biaya konsumsi, dan biaya lainnya selama masih berada di lingkungan tempat kerja. Informasi lebih lanjut terdapat dalam Tabel 6. 
Journal of Regional and Rural Development Planning (Jurnal Perencanaan Pembangunan Wilayah dan Perdesaan) Februari 2020, 4 (1): 31-42

Tabel 6. Dampak ekonomi lanjutan

\begin{tabular}{llrlll}
\hline Tenaga Kerja & $\begin{array}{l}\text { Jumlah } \\
\text { Kerja } \\
\text { (orang) }\end{array}$ & $\begin{array}{r}\text { Tenaga } \\
\text { Lokal }\end{array}$ & $\begin{array}{l}\text { Total } \\
\text { pengeluaran TK di kawasan } \\
\text { wisata (Rp) }\end{array}$ & $\begin{array}{l}\text { Rata-rata } \\
\text { Pengeluaran } \\
\text { kawasan }\end{array}$ & $\begin{array}{l}\text { di } \\
\text { Ekonomi } \\
\text { Lanjutan }\end{array}$ \\
\hline Rumah Makan & 13 & $20,879,200$ & 28.6 & $77,762,000$ \\
Restoran & 15 & $29,700,000$ & 40.8 & $181,552,000$ \\
Kebersihan & 12 & $3,700,000$ & 5.1 & $2,255,000$ \\
Karcis FDS & 5 & $3,650,000$ & 5.0 & 914,000 \\
Keamanan & 10 & $3,900,000$ & 5.4 & $2,087,000$ \\
Petugas Parkir & 10 & $3,750,000$ & 5.1 & $1,930,000$ \\
Penjaga Toilet & 8 & $3,500,000$ & 4.8 & $1,345,000$ \\
Tim Pelaksana & 20 & $3,800,000$ & 5.2 & $3,963,000$ \\
\hline Total & & & & $271,808,000$ \\
\hline
\end{tabular}

Jumlah tenaga kerja lokal yang terdapat pada berbagai unit usaha yang terdapat di kawasan Danau Sentani yaitu sebanyak 93 orang. Tenaga kerja tersebut terdiri dari penduduk asli lokal (Suku Sentani) dan sukusuku lain yang berdomisili di sekitar kawasan tersebut. Keahlian para tenaga kerja tersebut secara umum masih belum baik, hal tersebut disebabkan oleh tidak adanya penilaian kualitas dan kemampuan terhadap karyawan yang dilakukan oleh pemilik usaha.

\section{Nilai Efek Pengganda (Multiplier Effect)}

Dampak ekonomi pengganda yang dihasilkan oleh aktivitas wisata di Danau Sentani yaitu berupa dampak ekonomi terhadap masyarakat lokal, peningkatan unit usaha, penyediaan lapangan kerja, peningkatan pendapatan tenaga kerja, dan peningkatan unit usaha lainnya (META, 2001). Hasil analisis terhadap pendapatan masyarakat lokal (Keynesian Income Multiplier) sebesar 0.93, artinya apabila terjadi peningkatan pengeluaran wisatawan sebesar Rp100,000, maka akan terjadi peningkatan pendapatan masyarakat lokal sebesar Rp93,000. Makna lain dari nilai 0.93 memberikan gambaran wisata Danau Sentani menghasilkan dampak ekonomi yang rendah terhadap aktivitas wisata lokal. Hal tersebut disebabkan adanya kebocoran ekonomi wilayah di lokasi wisata. Informasi lebih lanjut terdapat pada Tabel 7.

Nilai Ratio Income Multiplier tipe I dan II tidak berbeda jauh yaitu masing-masing sebesar 1.32 dan 1.37, artinya apabila peningkatan pengeluaran wisatawan sebesar
Rp100,000, maka akan terjadi peningkatan pendapatan unit usaha sebesar Rp132,000 dan Rp137,000 terjadi peningkatan pendapatan tenaga kerja. Nilai Ratio Income Multiplier tipe I dan II sebesar 1.32 dan 1.37 bermakna jumlah aliran pengeluaran wisatawan mampu meningkatkan unit usaha dan menciptakan lapangan kerja. Income Multiplier secara umum mengukur tambahan pendapatan (upah, sewa, bunga, dan profit) dalam perekonomian sebagai hasil dari peningkatan pengeluaran wisatawan (Cooper et al., 1998). Hasil penelitian Dristasto dan Anggraeni (2013) menunjukkan dampak ekonomi kawasan Pulau Tidung di Kepulauan Seribu sebesar 0.28. Hal tersebut menunjukkan bahwa aktivitas wisata di wilayah tersebut belum mampu memberikan manfaat bagi masyarakat setempat.

Tabel 7. Nilai multiplier dari aliran uang kegiatan wisata Danau Sentani

\begin{tabular}{lc}
\hline Kategori & Nilai \\
\hline Keynesian Income Multiplier & 0.93 \\
Ratio Income Multiplier, Tipe I & 1.32 \\
Ratio Income Multiplier, Tipe II & 1.37 \\
\hline
\end{tabular}

\section{Strategi Pengembangan Wisata Danau Sentani}

Upaya untuk pengembangan wisata Danau Sentani pada masa yang akan datang, maka dibutuhkan strategi pengembangan yang baik dan berkelanjutan. Strategi pengembangan disusun ke dalam beberapa tahapan kegiatan, yang terdiri dari: 1) penetapan tujuan, 2) penentuan pihak yang bertanggung jawab (stakeholder), 3) penentuan aspek-aspek atau bidang-bidang pengembangan, dan 4) strategi alternatif pengembangan. Dalam penelitian ini, 
untuk mengetahui alternatif arah pengembangan pengelolaan wisata alam di kawasan Danau Sentani diambil responden dari stakeholder atau pihak-pihak yang terkait dengan pengelolaan wisata alam.

Responden dipilih dari orang-orang yang kompeten dibidangnya dan memiliki pengetahuan mengenai pengelolaan wisata alam di kawasan Danau Sentani. Responden terdiri dari pihak Dinas Pariwisata dan Kebudayaan (1 orang), lembaga masyarakat adat (1 orang), pihak distrik (1 kecamatan), LSM Lokal (1 orang) dan unit usaha yang terkait wisata alam di kawasan Danau Sentani (2 orang). Selanjutnya para responden mengidentifikasi permasalahan dan menentukan aspek-aspek atau bidang-bidang serta strategi yang relevan dalam pengelolaan Danau Sentani kedepan.
Hasil penelitian menunjukkan bahwa upaya untuk mengembangkan wisata Danau Sentani, maka stakeholder yang paling berperan adalah pemerintah daerah diikuti lembaga masyarakat adat, swasta, dan akademisi/LSM. Hal tersebut disebabkan oleh karakteristik masyarakat disekitar wilayah Kabupaten Jayapura masih memiliki ketergantungan yang sangat besar terhadap peran pemerintah dalam memajukan seluruh perekonomian termasuk sektor pariwisata.

Upaya pengembangan wisata Danau Sentani sebagai wisata yang berbasis lingkungan, maka aspek keberlanjutan ekosistem dan ekologi yang terdapat di dalam kawasan Danau Sentani perlu mendapat perhatian yang serius oleh berbagai stakeholder di bawah. Informasi lebih lanjut terdapat dalam Gambar 2.

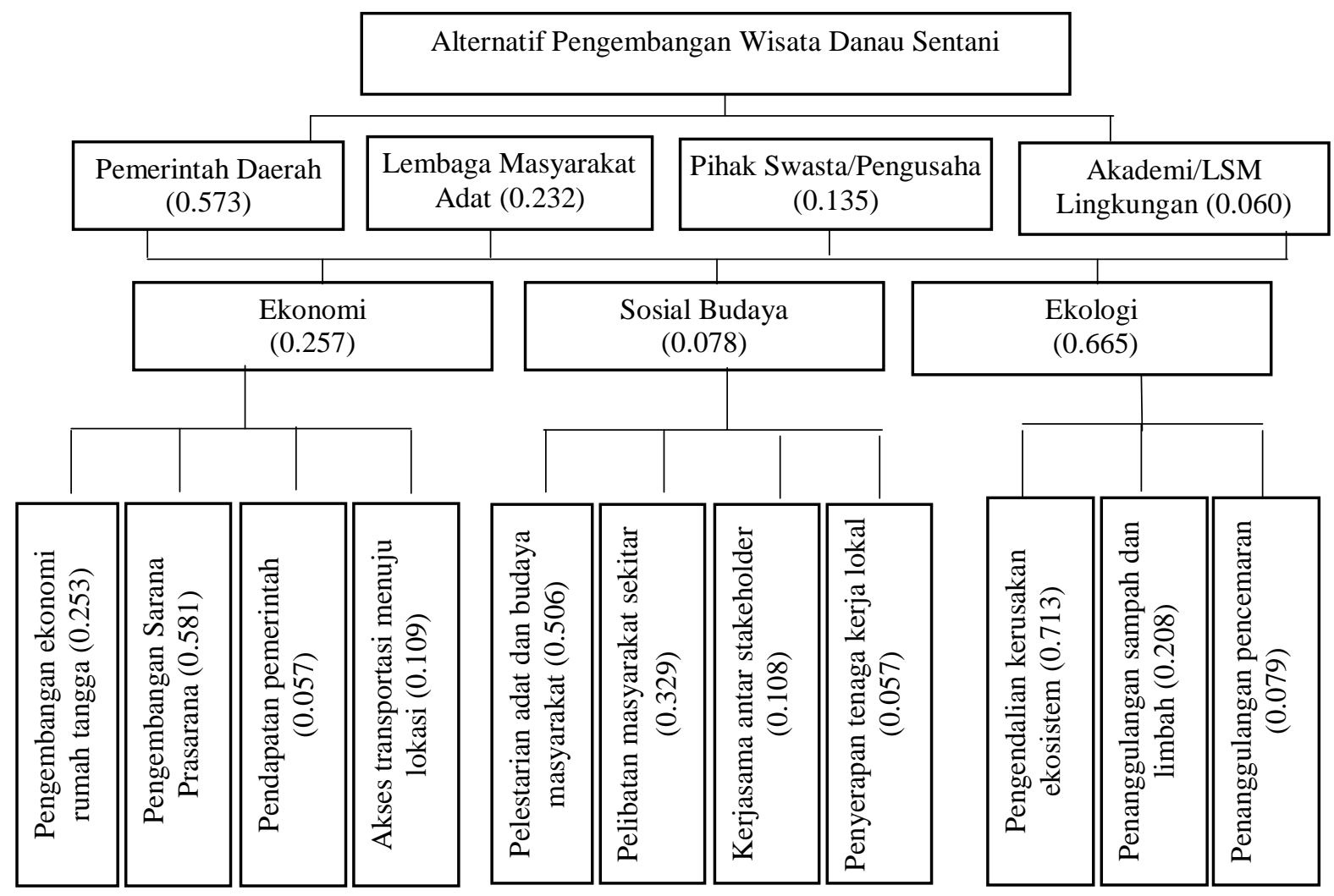

Gambar 2. Struktur hierarki alternatif pengembangan wisata Danau Sentani

Hal tersebut juga didukung dengan hasil analisis yang menunjukkan bahwa aspek ekologi memiliki nilai sebesar 0.665 atau disebut aspek prioritas. Hasil penelitian Ramadanta dan Basri (2011) menunjukkan bahwa upaya konservasi terhadap lingkungan alam adalah hal yang wajib dan mendasar yang harus dijaga dalam rangka pengembangan potensi wisata di Danau Poso Provinsi Sulawesi Tengah. 
Alternatif pengembangan wisata Danau Sentani berdasarkan aspek ekonomi, sosial budaya, dan ekologi yang harus diutamakan adalah pengendalian kerusakan ekosistem dan penanggulangan pencemaran Danau Sentani. Hal tersebut menunjukkan bahwa wisata Danau Sentani adalah jenis wisata berbasis alam, sehingga kelestarian ekosistem tersebut sangat penting dalam keberlanjutan pengembangan wisata. Hal tersebut sejalan dengan penelitian Endah dan Najib (2017) pemanfaatan Danau yang dilakukan secara berlebihan untuk berbagai kepentingan ekonomi akan menyebabkan terjadinya degradasi ekologi. Desta (2018), menyatakan bahwa pemerintah harus memperkenalkan program pengelolaan dan konservasi untuk pemanfaatan danau yang efisien dan berkelanjutan. Selanjutnya jika hal ini tetap dibiarkan, akan dapat memicu terjadinya bencana akibat kerusakan alam serta memarjinalisasikan dan memiskinkan sekelompok masyarakat.

Aspek prioritas selanjutnya adalah pengembangan sarana dan prasarana penunjang wisata, pengembangan sarana dan prasarana untuk desa lainnya seperti dermaga dapat memicu wisatawan yaitu dermaga sebab jika banyak dibangun dermaga-dermaga diberbagai desa disekitaran Danau Sentani maka dapat memicu wisatawan untuk berkunjung sehingga pengeluaran dari wisatawan tersebut dapat menjadi nilai ekonomi bagi masyarakat, dalam penelitian Widhijanto dan Tisnaningtyas (2018) faktor yang mendukung pengembangan destinasi wisata danau apabila adanya peningkatan dermaga. Dibangunnya sarana dan prasarana penunjang di Danau Sentani untuk wisatawan dapat memicu pendapatan bagi masyarakat, yaitu dengan adanya akses berkeliling danau, secara otomatis wisatawan akan berkunjung dan secara tidak langsung akan membangkitkan ekonomi-ekonomi lainnya seperti pembukaan rumah makan, restoran, souvenir, atau bahkan dapat membuka resort bagi para wisatawan yang ingin menginap. Prasetya dan Ansar (2017) menyatakan strategi dan pengembangan kawasan wisata yang perlu diterapkan adalah peningkatan sarana dan prasarana. Pengembangan pariwisata danau dari aspek sarana dan prasarana merupakan kategori tertinggi yang dipilih oleh responden dalam pengembangan kawasan pariwisata (Siregar et al., 2018).

Pengembangan ekonomi masyarakat merupakan prioritas selanjutnya yang harus diperhatikan dalam pengembangan wisata Danau Sentani kedepannya. Chidammodzi (2015), menyatakan bahwa strategi dan pengelolaan danau terhambat oleh sumberdaya manusia yang tidak memadai serta aliran dana yang tidak stabil. Masyarakat lokal dalam aktivitas wisata ini memegang peranan untuk mengoptimalkan pendapatan sehingga masyarakat harus mampu mengolah keistimewaan produk yang dimiliki agar mampu bersaing, selain itu pemerintah lokal dan masyarakat dapat berperan aktif dengan mengembangkan dan mendorong unit-unit ekonomi (BUMDES) dan koperasi dalam mendukung aktivitas wisata, dengan begitu dapat mengurangi kebocoran ekonomi.

Prioritas selanjutnya yaitu pelestarian adat masyarakat, nilai-nilai budaya dapat diartikulasikan sebagai salah satu kekuatan penggerak ekonomi (driving force of economy) bagi kemajuan wilayah (Mungmachon, 2012). Kebudayaan yang menguntungkan dan dapat berfungsi mempertahankan eksistensi masyarakat dalam lingkungan alam, biologi dan fisik, akan diteruskan ke generasi berikutnya hingga terbentuk tradisi (Ningrum, 2012). Selanjutnya pelibatan masyarakat dan seluruh stakeholder sangat penting bagi perkembangan wisata Danau Sentani ke depannya sebab dibutuhkan koordinasi semua pihak terkait pengembangan wisata tersebut agar selaras dengan konsep ekowisata yaitu kelestarian lingkungan, kesejahteraan masyarakat, dan kelestarian budaya masyarakat.

\section{KESIMPULAN}

Analisis nilai ekonomi Danau Sentani menunjukkan bahwa variabel yang berpengaruh signifikan positif terhadap jumlah kunjungan 
wisata yaitu meliputi pendapatan, kebersihan, dan pendidikan. Sedangkan yang berpengaruh signifikan negatif meliputi biaya perjalanan, jarak tempuh, dan usia. Kegiatan wisata di kawasan Danau Sentani menghasilkan nilai ekonomi sebesar Rp875,166,460 juta per tahun. Kontribusi ekonomi yang dirasakan bagi masyarakat lokal masih relatif rendah. Hal ini dikarenakan kebocoran ekonomi yang terjadi masih sangat besar terutama untuk transportasi dan konsumsi sehingga manfaat ekonomi yang dibawa wisatawan belum maksimal.

Kegiatan wisata Danau Sentani mampu memberikan dampak ekonomi bagi masyarakat sekitar walaupun relatif masih rendah yang ditunjukkan dengan nilai income multiplier yang dihasilkan sebesar 0.93. Nilai Keynesian Multiplier ini masih dapat terus ditingkatkan dengan memperkecil kebocoran pada biaya pengeluaran wisatawan dan meningkatkan penyediaan barang yang diperlukan wisatawan oleh unit usaha yang ada agar dapat menarik minat wisatawan untuk membeli.

Strategi pengembangan wisata Danau Sentani yang diusulkan adalah yang berbasis ekologi khususnya pengendalian kerusakan ekosistem, didukung oleh peran stakeholder pemerintah daerah sebagai pembuat regulasi dan bertanggungjawab untuk memajukan kesejahteraan para pelaku usaha yang terlibat di dalam seluruh aktivitas terkait wisata Danau Sentani.

\section{SARAN}

Kontribusi ekonomi Wisata Danau Sentani terhadap kesejahteraan masyarakat masih rendah. Oleh karena itu pemerintah Kabupaten perlu memperbanyak kegiatan di kawasan tersebut dalam upaya memperkecil kebocoran ekonomi dan memperluas manfaat ekonomi bagi masyarakat lokal. Selain itu, perlu juga memperhatikan aspek ekologi yang merupakan variabel utama yang berperan dalam menciptakan keberlanjutan wisata Danau Sentani sehingga meningkatkan peran seluruh stakeholder untuk menjaga kelestarian sumberdaya tersebut.

\section{DAFTAR PUSTAKA}

Chidammodzi, C. L. \& Muhandiki, V. S. (2015). Development of indicators for assessment of Lake Malawi Basin in an Integrated Lake Basin Management (ILBM) framework. Nagoya University. International Journal of the Commons, 9 (1), 209-236

Cooper, C., Fletcher J, Gilbert, D., Shepherd, R., \& Wanhil, S. (1998). Tourism: Principles and Practice. Second Edition. Addison-Wesley, Longman.

Desta, Y. (2018). Analysis of Economic Value of Lake Ziway: An Application of An Application of Contingent Valuation Method. Journal of Resources Development and Management, 40, 5566.

Dritasto, A. \& Anggraeni, A. A. (2013). Analisis Dampak Ekonomi Wisata Bahari Terhadap Pendapatan Masyarakat di Pulau Tidung. Jurnal Online Institut Teknologi Nasional Reka Loka, 1 (1), 18.

Dinas Pariwisata dan Kebudayaan Kabupaten Jayapura. (2019). Jumlah wisatawan nusantara dan mancanegara: Jayapura.

Endah, H. N. \& Nadjib, M. (2017). Pemanfaatan dan Peran Komunitas Lokal dalam Pelestarian Danau Maninjau. Jurnal Ekonomi dan Pembangunan, 25 (1), 55-67

Fauzi, A. (2014). Valuasi Ekonomi dan Penilaian Kerusakan Sumberdaya Alam dan Lingkungan. IPB Press.

[META] Marine Ecotourism for Atlantic Area. (2001). Planning for Marine Ecotourism in The EU Atlantic Area. University of The West of England, Bristol.

Mungmachon, M. R. (2012). Knowledge and Local Wisdom: Community Treasure. International Journal of Humanities and Social Science, 2 (13), 174-181.

Ningrum, E. (2012). Dinamika Masyarakat Tradisional Kampung Naga di Kabupaten Tasikmalaya. Jurnal Mimbar, 28 (1), 4754. 
Prasetya, D. B. \& Ansar, Z. (2017). Pengembangan Desa Wisata Berbasis Community Based Tourism Pada Kawasan Danau Ranau Lumbok Seminung Lampung Barat. Institut Teknologi Sumatera. Jurnal Plano Madani, 6 (1), 60-72

Ramadanta, A. \& Basri, I. S. (2011). Pendekatan Ecoregion Dalam Pengembangan Kawasan Wisata Studi Kasus Penataan Kawasan Wisata Danau Poso. Jurnal ruang, 3 (1),1-13.

Ritonga, D. A (2018). Nilai Ekonomi Danau Naga Sakti Berdasarkan Pendekatan CVM untuk kegiatan wisata di Desa Dosan Kecamatan Pusako Kabupaten Siak. Pekan Baru: Universitas Riau.

Rustiadi, E., Saefulhakim, S., \& Panuju, D. R. (2011). Perencanaan dan Pengembangan Wilayah. Yayasan Pustaka Obor Indonesia.

Saaty, T. L. (1994). How to Make a Decision : The Analytic Hierarchy Process. Institute for Operations Research and the Management Science, 6 (24), 19-43.

Siregar, H. \& Dwi, W. (2008). Dampak Pertumbuhan Ekonomi Terhadap Penurunan Jumlah Penduduk Miskin. Institut Pertanian Bogor.

Siregar, R. A., Winanegara, H. W., \& Hermantoro, H. (2018). Pengembangan Kawasan Pariwisata Danau Toba, Kabupaten Toba Samosir. Tata Loka, 20 (2), 100-112.

Soleh, A. (2017). Strategi pengembangan potensi desa. Jurnal Sungkai. 5 (1), 3252.

Tarigan, R. (2007). Ekonomi Regional: Teori dan Aplikasi. Bumi Aksara.

Yakup, A. P. (2019). Pengaruh Sektor Pariwisata Terhadap Pertumbuhan Ekonomi di Indonesia. Tesis. Universitas Airlangga
Walukow, A. F., Djokosetiyanto, D., Kholil, \& Soedarma, D. (2008). Analisis Strategi Pengelolaan dan Peranan Lembaga dalam Rangka Konservasi Danau Sentani Jayapura. Media Konservasi, 13 (1), 2131.

Widhijanto, A. A. \& Tisnaningtyas, E. Y. (2018). Identifikasi Kawasan Permukiman Pendukung: Analisis Proximity Pengembangan Destinasi Wisata Danau Toba. Jurnal Neo Teknika, 4 (1), 11-19. 